\title{
INTERVENCIÓN DE LA ADMINISTRACIÓN MUNICIPAL EN CUANTO A LA INSTALACIÓN DE EXPLOTACIONES GANADERAS: ADAPTACIÓN A LA NORMATIVA EUROPEA EN MATERIA DE BIENESTAR ANIMAL ${ }^{1}$
}

\section{Concha Castro Álvarez ${ }^{2}$}

\section{Índice de este documento:}

I. Competencias que tradicionalmente han asumido los municipios en materia de bienestar animal.

II. La problemática de la instalación de las explotaciones ganaderas: conciliación de los intereses de los granjeros, del resto de habitantes del municipio y del bienestar animal.

- Condiciones de ubicación de las instalaciones ganaderas

- Adaptación de las instalaciones ganaderas a la normativa europea

- Cambios normativos llevados a cabo por el legislador autonómico catalán para facilitar el cumplimiento de la normativa europea.

\footnotetext{
${ }^{1}$ Estos apuntes se corresponden a parte de las explicaciones que fueron objeto de la sesión del Master del día 19 de abril de 2012 que tenía por objeto las Competencias municipales en materia de bienestar animal

2 Técnica Superior en Derecho del Ayuntamiento del Prat de Llobregat (Barcelona), actualmente en comisión de servicios como Letrada de la Sala de lo Contencioso Administrativo del Tribunal Supremo
} 


\section{Competencias que tradicionalmente han asumido los municipios en materia de bienestar animal. Breve introducción}

El papel desempeñado por las entidades locales, concretamente, por los municipios, en relación a los animales de compañía, ha sido muy significativo y, todavía lo sigue siendo, en el panorama normativo del siglo XX. A ellas les fueron encomendadas una serie funciones, generalmente de carácter ejecutivo, relacionadas directa o indirectamente, con cuestiones de índole sanitaria, como fueron la recogida y sacrificio de animales abandonados, la identificación, la matriculación, las cartillas sanitarias, la inspección o el censo.

Pese a ser el aspecto sanitario, el núcleo esencial de las distintas regulaciones que de algún modo se acercaron al sector de los animales domésticos hasta 1985, no es menos cierto que también estuvo presente la faceta de la protección, entre otras representada por la Real Orden Circular de 31 de julio de 1929, en la que se recogían las distintas infracciones por maltrato ocasionado a animales domésticos, siendo las competencias municipales, normalmente recaídas sobre la figura del alcalde, promover el respeto y la defensa de los animales e imponer las sanciones por la comisión de las infracciones, sin perjuicio de las competencias de los Gobernadores Civiles.

Nuestro sistema jurídico actual requiere que sea el legislador estatal o autonómico, en virtud del reparto competencial de los artículos 149 y 148 de la Constitución, el que concrete las competencias que deberán ser ejercidas por las Corporaciones Locales. El artículo 25.2 de la Ley 7/1985, de 2 de abril, reguladora de las bases de régimen local, dispone que "el municipio ejercerá, en todo caso, competencias, en los términos de la legislación del Estado y de las Comunidades Autónomas". En este sentido, debe decirse que dicha Ley no supuso, para los municipios, nueva atribución de competencias en el sector de los animales sino que, 
por el contrario, siguieron ejerciendo las funciones que hasta ese momento les habían atribuido otras normas.

En 1988, las Comunidades Autónomas comenzaron un proceso de regulación del sector de los animales domésticos, especialmente, de los animales de compañía, proceso que ha conducido a que al día de hoy todas se hayan dotado de una ley que aborda la materia. Puede decirse que estas leyes se han limitado a recoger y sistematizar las competencias de las que ya eran titulares los municipios con anterioridad: censo, recogida, mantenimiento y sacrificio de animales, vigilancia e inspección de los establecimientos de venta, guarda o cría. Ello quiere decir que los municipios han tratado la tenencia de animales de compañía mucho antes de la primera ley autonómica de protección, y lo han hecho desde una perspectiva casuística pues, a diferencia de las leyes autonómicas, que suelen tener unos objetivos más ambiciosos, las ordenanzas se han ocupado sobre todo de la tenencia y de los problemas concretos que de ella se derivan.

En cualquier caso y sintetizando, puede decirse que las competencias municipales en relación con los animales han comprendido estos dos grandes ámbitos: el sanitario y el de protección.

Dentro del ámbito sanitario, los municipios también han tenido atribuidas competencias en lo que se refiere a la concreta ubicación de las instalaciones ganaderas y, así, les ha correspondido decidir -con alguna que otra limitación, como luego veremos- el emplazamiento de dichas instalaciones y el otorgamiento de las licencias preceptivas.

Pues bien, a continuación vamos a detenernos en esta cuestión para tratar con un poco más de detenimiento este tipo concreto de competencias que ejercen los municipios que, si bien en una primera aproximación, se sitúan dentro de la esfera sanitaria de las atribuciones que, en el sector de los animales, les corresponden, 
veremos que también está muy presente la faceta de la protección y que ha sido esta última justamente la que ha motivado los recientes cambios normativos en la materia.

\section{La problemática de la instalación de las explotaciones} ganaderas: conciliación de los intereses de los granjeros, del resto de los habitantes del municipio y del bienestar animal

En el periódico "La Vanguardia" del día 26 de febrero de 2012, apareció publicado un artículo en el que se abordaba la cuestión del precio que nuestra sociedad debía pagar por el bienestar animal. En dicho artículo se hacía referencia a la entrada en vigor de determinadas normas europeas -hace ya una década- que obligaban a los titulares de explotaciones de animales destinados al consumo humano directamente, o a la producción de bienes destinados a idéntico consumo, a introducir determinados cambios en dichas instalaciones con la finalidad de que los animales que las ocupan pudieran disponer de mejores condiciones.

Dicho artículo señalaba lo siguiente:

"El bienestar animal tiene un precio, y su factura será muy cara. Las normas europeas en la materia entraron en vigor hace una década, pero el desinterés, la compleja adaptación técnica o la falta de recursos de los granjeros han dejado la adecuación para el último momento. El problema es que la exigencia para cumplir las normas llega en plena crisis.

La Coordinadora de Organizaciones de Agricultores y Ganaderos (COAG) alerta de que en España pueden cerrar un 40\% de las granjas de gallinas ponedoras de huevos y que en las explotaciones de cerdos se precisa invertir 700 millones para afrontar los cambios necesarios. La Generalitat, pese a sus números rojos, destinó el año pasado 15 millones de euros a subvencionar créditos a coste cero 
a los ganaderos y ha tenido que reservar otros 12 millones para este fin este año.

Las alarmas se encendieron cuando, el 26 de enero, la UE envió un requerimiento a España (y a otros 12 países) por la deficiente aplicación de la legislación en materia de bienestar animal. Antes del 1 de enero de este año se tenian que haber retirado las viejas e inadecuadas jaulas para las gallinas ponedoras. Pero, pese a los reiterados Ilamamientos de la UE, sus peticiones no han surtido efecto. El expediente puede dar lugar a un procedimiento de infracción y sanción, con lo que la factura del bienestar animal puede encarecerse más. "Los ganaderos se han dormido, van al ralentí en el cumplimiento de las exigencias europeas de bienestar animal; y de ahí el ultimátum de la UE", dice Carmen Méndez, vicepresidenta de la Asociación para la Defensa de los Derechos de los Animales (ADDA).

La normativa sobre gallinas ponedoras de huevos para consumo directo (en vigor desde el 2002) obliga a instalar jaulas más amplias (750 cm2 por animal, un 35\% más grandes que ahora) y a dotarlas de nido, yacija para escarbar y un sistema de recorte de uñas; $y$, además, los animales pueden ponerse en el suelo (cubiertos). Por su parte, las cerdas, a partir de los 28 días de gestación, deben estar en grupo, y no en estancias individualizadas como ahora (aunque en este caso la adaptación debe hacerse antes del 31 de diciembre del 2012). Todos estos cambios suponen fuertes inversiones, nuevos modos de manejo y la aplicación de planes de mejora. Sin embargo, el proceso de adaptación en las granjas acumula muchos retrasos.

En Catalunya, están afectadas 118 explotaciones de gallinas ponedoras (con 4,5 millones de animales), y se calcula que sólo un tercio de ellas (y de los animales) cumple con las exigencias; otro tercio está en proceso de adecuación, y el resto tiene la tarea pendiente, según estimaciones de José Segura, responsable del sector avícola de Unió de Pagesos. 
La inversión necesaria (en Catalunya) en las granjas de gallinas ponedoras estaría entre 45 y 70 millones de euros, mientras que las 1.650 granjas y las 450.000 cerdas gestantes precisan unos 90 millones. Ahora, sólo el $25 \%$ de estas últimas granjas están adaptadas (aunque tienen tiempo hasta final de año).

"Lamentablemente, creemos que habrá granjas que no puedan adaptarse y tendrán que cerrar", explica Joaquim Xifra, jefe del Servei d'Ordenació Ramadera de la Generalitat, quien, pese a todo, se resiste a que haya cierres irremisibles, pues, como alternativa, los granjeros más rezagados tienen la opción de "sacar gallinas" y luego pedir préstamos bonificados y poner en marcha planes de mejora con fondos europeos.

"No tiene por qué haber cierres. El problema puede resolverse si una granja con 1.000 gallinas se queda en 700; aunque, eso sí, supone una pérdida de capacidad productiva", coincide con él Anna Toda, directora de la Federació Avícola Catalana.

"Hay voluntad del sector para adaptarse, el problema es la falta de capacidad económica para hacerlo", dice Rossend Saltiveri, responsable del sector porcino de UP. "Lo fundamental es que las líneas de ayuda salgan adelante realmente y se den facilidades para hacer la adaptación", agrega.

Los granjeros se quejan de que la orden de ayudas del Govern del 2012 (préstamos bonificados a coste cero) aún no ha sido publicada. Igualmente, se exculpan diciendo que el año pasado, en muchas ocasiones, no pudieron formalizar el crédito porque no tuvieron tiempo para disponer del aval preceptivo. Además, critican los obstáculos urbanisticos con que suelen tropezar en los ayuntamientos para ganar espacio en las granjas.

Pero para reducir los trámites, el Govern ha modificado la ley de Urbanisme, pues en este caso la adecuación de las actividades no comportan un aumento de la capacidad productiva. Otro motivo de ataque es que "los fabricantes están 
desbordados y no tienen capacidad de suministro de materiales", dice Saltiveri. El Ministerio de Agricultura, Alimentación y Medio Ambiente ha urgido a las comunidades a que actúen, para evitar que lleguen sanciones de la $U E$, y ha recordado que deben hacer las inspecciones para que se cumpla la norma.

Incluso, para urgir los cambios, Agricultura permite prorrogar la adaptación a las granjas de gallinas hasta el 31 de julio siempre y cuando los huevos no vayan al consumo directo, sino a los restaurantes o la industria. La medida puede llevar a la confusión, y por eso Anna Toda, de la Federació Avícola, insiste en que la calidad de los huevos está siempre garantizada. Es decir que, aunque procediera de una granja no adaptada, "el huevo sería igualmente bueno, sano y nutritivo". "El granjero es el primer interesado en tener en condiciones a sus animales", sostiene. Otras fuentes señalan que muchos granjeros vieron siempre la norma como una imposición.

"Los retrasos en la adaptación no tienen justificación, porque los ganaderos tienen ayudas de la UE. La industria ha condenado a los animales a ser máquinas de producir, simples objetos de rentabilidad, y ha olvidado sus necesidades, en la cría, en el transporte o en el sacrificio", cree Méndez. Al 64\% de los consumidores les preocupa el bienestar animal pero sólo en un $2 \%$ elige la compra según ese criterio, "debido a la falta de información", dice".

Vemos que en este artículo, uno de los problemas que han objetado los titulares de explotaciones ganaderas son los obstáculos urbanísticos que ponen, en ocasiones, los Ayuntamientos. Pues bien, el papel que desempeñan los municipios en cuanto a las condiciones de los animales en las granjas y explotaciones ganaderas se concreta en un doble aspecto:

- Tienen atribuidas competencias en materia de ordenación urbanística en lo que respecta a la ubicación de las instalaciones ganaderas. Nuestro ordenamiento 
jurídico ha pretendido asegurar que la implantación de aquellas actividades potencialmente generadoras de molestias, en cuanto a olores o por razones higiénicas o sanitarias, se llevase a cabo alejada de los núcleos habitados de las poblaciones, y a su vez, separadas entre sí y entre otro tipo de instalaciones a los efectos de evitar posibles focos de contagio. En este sentido, la normativa sectorial ha venido estableciendo las distancias que en todo caso dichas explotaciones debían respetar -a las que luego nos referiremos- $y$, por supuesto, el planificador urbanístico debía tenerlas en cuenta a la hora de elaborar el plan de la ciudad o del municipio. Por tanto, puede decirse que un primer obstáculo con que se pueden encontrar los titulares de explotaciones ganaderas es el relativo al cumplimiento de esas distancias a las que nos referíamos pero debería quedar claro que el establecimiento de las mismas no obedece a un capricho del legislador o del planificador.

- Tienen atribuidas competencias en materia de otorgamiento de licencias de actividad y de obras, esto es, a los efectos de verificar que dichas instalaciones se llevan a cabo de acuerdo con el planeamiento y el resto de la normativa vigente).

Seguidamente abordaremos estas cuestiones separadamente.

\section{a) Ubicación de las instalaciones ganaderas}

Como sabemos, forma parte de las potestades del planificador -municipal y autonómico- la regulación de los usos y las actividades que se desarrollan en nuestras ciudades y pueblos y su concreta ubicación.

En esta potestad, el planificador no encuentra más límite que la de la llamada fuerza normativa de lo fáctico - no puede, por ejemplo, clasificar como suelo rústico lo que a todas luces reúne las condiciones de un suelo urbano- y la de las normas de superior jerarquía que resulten de aplicación, que pueden establecer determinados límites o condicionantes que será forzoso respetar. 
Por tanto, el planificador municipal -que normalmente es el que inicia el procedimiento de redacción del plan- deberá regular la ciudad teniendo en cuenta las características de la misma y los intereses de sus habitantes, respetando siempre la regulación que se contenga en normas de Derecho comunitario, estatal o autonómico, de superior jerarquía, que puedan incidir sobre el territorio.

Y entre estas especificaciones o condicionantes que forzosamente deberá respetar se encuentra la regulación de las condiciones a que ha de sujetarse la ubicación de las instalaciones ganaderas. Dichas condiciones se hallan reguladas tanto a nivel estatal como autonómico, y entre las mismas debemos de destacar -en lo que tienen de directa afectación sobre las competencias municipales-, las concretas distancias de las instalaciones ganaderas entre sí, entre otras instalaciones que puedan constituir fuente de contagio y respecto del casco urbano de la población.

A efectos ilustrativos, podemos destacar las siguientes normas:

En cuanto a la normativa estatal:

- Real Decreto $1547 / 2004$, de 25 de junio, por el que se establecen normas de ordenación de las explotaciones cunículas ${ }^{3}$ : fija una distancia mínima de $500 \mathrm{~m}$ entre este tipo de explotaciones así como entre éstas y otras instalaciones que puedan constituir fuente de contagio.

- Real Decreto 1084/2005, de 16 de septiembre, de ordenación de la avicultura de carne $\mathrm{4}^{4}$ : se establece una distancia de $500 \mathrm{~m}$ con respecto a este tipo de explotaciones o con respecto a cualquier instalación que pueda representar un riesgo higiénico-sanitario.

\footnotetext{
${ }^{3}$ La norma se puede consultar en la página www.derechoanimal.info, en el siguiente enlace: http://www.derechoanimal.info/bbdd/Documentos/922.pdf

${ }^{4}$ La norma se puede consultar en la página www.derechoanimal.info en el siguiente enlace: http://www.derechoanimal.info/bbdd/Documentos/175.pdf
} 
- Real Decreto 324/2000, de 3 de marzo, por el que se establecen las normas básicas de ordenación de las explotaciones porcinas ${ }^{5}$ : fija unas distancias de separación a los núcleos urbanos y a otras instalaciones que oscilan de los $500 \mathrm{~m}$, al $1 \mathrm{~km}$ y $2 \mathrm{~km}$, en función del grupo en que se encuentre incluida la explotación (inclusión que, a su vez, viene determinada por la capacidad de la explotación, de acuerdo con los criterios que se fijan en el mismo Real Decreto).

En cuanto a la normativa autonómica catalana

- Decreto 61/1994, de 22 de febrero, que regula las condiciones mínimas a cumplir por las explotaciones ganaderas ${ }^{6}$. Esta norma exige respetar la distancia sanitaria conveniente que establezcan las disposiciones vigentes (respecto a otras instalaciones ganaderas e industrias agroalimentarias).

- Orden de 7 de abril de 1994 sobre regulación de las explotaciones porcinas, avícolas, cunícolas y bovinas ${ }^{7}$. Se establecen distancias mínimas en función de la especie:

- Instalaciones porcinas: para la instalación de una nueva explotación porcina será condición indispensable que ésta mantenga una distancia adecuada en relación con otras explotaciones porcinas, mataderos, salas de deshecho, industrias cárnicas, centros de aprovechamiento de cadáveres $\mathrm{u}$ otras instalaciones relacionadas con la producción porcina que se puedan considerar fuente de

5 La norma se puede consultar en la página www.derechoanimal.info en el siguiente enlace:http://www.derechoanimal.info/bbdd/Documentos/992.doc

6 La norma se puede consultar en la página www.derechoanimal.info, en el siguiente enlace: http://www.derechoanimal.info/bbdd/Documentos/447.doc

7 La norma se puede consultar en la página www.derechoanimal.info, en el siguiente enlace: http://www.derechoanimal.info/bbdd/Documentos/446.pdf 
contagio. En caso de que esta distancia sea inferior a 1.000 metros deberán justificarse las medidas específicas y suficientes adoptadas para evitar la difusión de enfermedades.

- Instalaciones avícolas: establece la misma distancia que en el apartado anterior, $1000 \mathrm{~m}$.

- Instalaciones cunícolas: en este caso, la Orden determina que para la instalación de nuevas explotaciones cunícolas de más de 30 conejos será condición indispensable que la explotación mantenga una distancia adecuada en relación con otras explotaciones cunícolas, mataderos, salas de deshecho, industrias cárnicas, centros de aprovechamiento de cadáveres $u$ otras instalaciones relacionadas con la producción cunícola que se puedan considerar fuente de contagio. Cuando estas distancias sean inferiores a 500 metros deberán justificarse las medidas de protección específicas y suficientes adoptadas para evitar la difusión de enfermedades.

- Instalaciones bovinas: no se establece distancia mínima sino simplemente se señala que habrá de mantener una distancia adecuada en relación con otras explotaciones bovinas, mataderos, salas de deshecho, industrias cárnicas, centros de aprovechamiento de cadáveres $u$ otras instalaciones relacionadas por la producción bovina que se puedan considerar fuente de contagio. En cualquier caso, deberán justificarse las medidas específicas y suficientes adoptadas para evitar la difusión de enfermedades.

- Decreto 136/2009, de 1 de septiembre. Este reglamento tiene como finalidad prevenir y reducir la contaminación de las aguas por nitratos que proceden de fuentes agrarias $y$, en consecuencia, aprueba el programa de actuación aplicable a las zonas vulnerables designadas en Cataluña y regula 
la gestión de las deyecciones ganaderas y otros fertilizantes en todo el ámbito de Cataluña. Entre otras consideraciones, regula las distancias mínimas que deberán respetar las instalaciones permanentes de almacenaje que pertenezcan a una determinada explotación ganadera y que esté ubicada en un emplazamiento diferente al del resto de instalaciones de la explotación.

Esto significa pues, que el redactor del planeamiento urbanístico deberá tener en cuenta esta normativa sectorial y las distancias establecidas a la hora de regular la concreta ubicación de las instalaciones ganaderas. Significa también que los titulares de las mismas deberán igualmente tenerlas en cuenta no sólo cuándo se implanten por primera vez sino también cuando les interese la ampliación de la actividad por las razones que sean.

\section{b) Adaptación de las instalaciones ganaderas a la normativa europea}

El Tratado de la Unión Europea reconoce a los animales la condición de seres sensibles y exige que se tenga en cuenta su bienestar en las políticas comunitarias. Puede decirse que el objetivo del bienestar animal no es un fin en si mismo para la Unión Europea, al menos hasta la fecha, sino un objetivo a tener en cuenta en todas las políticas comunitarias y que, en consecuencia, los Estados miembros deberán tener en cuenta en el ejercicio de las propias ${ }^{8}$.

\footnotetext{
${ }^{8}$ Es significativo que hasta ahora, las diferentes normas comunitarias hayan requerido de los Estados miembros que tengan en cuenta las exigencias en materia de bienestar de los animales pero que al mismo tiempo se haya previsto la salvedad de que en todo caso se respetarán las disposiciones legales o administrativas y las costumbres de los Estados miembros relativas, en particular, a ritos religiosos, tradiciones culturales y patrimonio regional. Es obvio que ambas exigencias pueden llegar a ser contradictorias por lo que las costumbres y las tradiciones "culturales" tienen prevalencia, en la Unión, por encima del bienestar de los animales.
} 
En este sentido, la Unión Europea, desde el último tercio del siglo pasado ha venido dictando normas de obligado cumplimiento para los Estados miembros que han tenido como finalidad establecer normas mínimas para la protección de los animales destinados al consumo humano. En la UE se estima que se crían 2.000 millones de aves y 300 millones de mamíferos destinados a consumo humano y que el $64 \%$ de los europeos se muestran preocupados por el bienestar animal ${ }^{9}$.

Pues bien, la normativa relativa a las condiciones de las gallinas ponedoras y de los cerdos exige que las instalaciones que ocupan estos animales cumplan con determinados requisitos. En el caso de las primeras, la normativa europea sobre normas mínimas de bienestar animal obliga a realizar reformas de las instalaciones antes del 1 de enero de 2012 y, en el caso de las instalaciones porcinas, dichas medidas habrán de ser adoptadas antes de enero del próximo año.

Pues bien, hasta el 1 de enero de 2012 cada gallina ponedora disponía de una jaula de $550 \mathrm{~cm} 2$ con una altura de $40 \mathrm{~cm}$. A partir de esa fecha, deberán ser $750 \mathrm{~cm} 2$ por gallina, con una altura de $45 \mathrm{~cm}$, y con nido. Además, los pasillos entre jaulas tendrán que ser superiores a $90 \mathrm{~cm}$. Por tanto, no solamente se tienen que cambiar las jaulas sino aumentar la superficie de la nave si se quiere mantener la misma capacidad productiva. (Directiva 1999/74/CE del Consejo de 19/07/1999, por la que se establecen las normas mínimas de protección de las gallinas ponedoras ${ }^{10}$; incorporada al ordenamiento español por el Real Decreto 3/2002, de 11 de enero) ${ }^{11}$.

En el caso de los cerdos, la nueva normativa entrará en vigor el 1 de enero de 2013. Hoy, el espacio por jaula para cerda reproductora es de 1,32 m2. A partir del año

\footnotetext{
9 Datos extraídos de "Comer animales", de Jonathan Safran Foer. Seix Barral. Biblioteca Los Tres Mundos. 2011.

10 Se puede consultar la norma en la página www.derechoanimal.info en el siguiente enlace:http://www.derechoanimal.info/bbdd/Documentos/94.pdf

11 Se puede consultar la norma en la página www.derechoanimal.info en el siguiente enlace:http://www.derechoanimal.info/bbdd/Documentos/167.pdf
} 
2013 la superficie mínima será de 2,25 m2 y se exigirá entre otros condicionantes, cambiar el suelo de la granja. (Directiva 2001/88/CE, de 23 de octubre de 2001, y Directiva 2001/93/CE de la Comisión, de 9 de noviembre de 2001, por las que se modifica la Directiva 91/630/CEE, relativa a las normas mínimas para la protección de cerdos; incorporadas al ordenamiento español por el RD 1135/2002, de 31 de octubre $\left.^{12}\right)$.

Aun cuando algunas de las Directivas que establecen estas exigencias son de hace ya varias décadas, las obras de adaptación a las mismas no han sido realizadas en todos los casos. En ocasiones, las razones que han dado los ganaderos es que el mantenimiento de la capacidad productiva exigía unas ampliaciones que, en algunos casos, entraba en contradicción con el planeamiento municipal. Se veían obligados, o bien a disminuir el número de ejemplares en la granja -con lo cual el negocio dejaba de ser rentable- o bien a cerrar la instalación si se encontraban con que la ampliación no podía ser realizada por entrar en contradicción con las condiciones que regulaba el planeamiento urbanístico.

\section{c) Cambios normativos llevados a cabo por el legislador autonómico catalán} para facilitar el cumplimiento de la normativa europea.

El legislador catalán, consciente de este problema, ha llevado a cabo una importante modificación legislativa que ha tenido por objeto la reducción de las "trabas" administrativas para realizar, en las instalaciones existentes, las obras necesarias para adaptarse a la normativa europea. En este sentido, debe decirse que ha modificado la normativa para facilitar no solamente la adaptación de las instalaciones ya existentes a la referida normativa sino para facilitar también la implantación de nuevas instalaciones.

\footnotetext{
${ }^{12}$ Se puede consultar la norma en la página web www.derechoanimal.info en el siguiente enlace: http://www.derechoanimal.info/bbdd/Documentos/176.pdf
} 
De forma simplificada $y$ en términos generales, podemos decir que la instalación de granjas está sometida a un régimen de intervención, en cuanto a su incidencia medioambiental o de ejercicio de la actividad, que puede ser más o menos estricto dependiendo de las dimensiones de la explotación. A mayor número de animales, mayor es el grado de intervención administrativa, requiriéndose autorización de la Administración autonómica para las instalaciones de mayor capacidad, y licencia municipal o comunicación previa al Ayuntamiento, en las de menos ${ }^{13}$.

Además de esta autorización correspondiente a la actividad, es exigible la preceptiva licencia de obras para ejecutar las que sean necesarias, y que se concede por el Ayuntamiento siempre que las obras sean conformes con la ordenación urbanística.

Cualquier granja en funcionamiento que necesite realizar obras para adaptarse a la normativa europea deberá volver a obtener las autorizaciones pertinentes por cuanto las concedidas inicialmente no permiten amparar las nuevas instalaciones. Es decir, si la actividad exigió de la concesión de una autorización por parte de la Administración autonómica y de la correspondiente licencia de obras municipal, el titular de la explotación deberá comunicar, por un lado, a la Administración autonómica los cambios introducidos, a fin de que si procede, se tramite la nueva autorización, y, por otro, deberá volver a solicitar la pertinente licencia de obras ante el Ayuntamiento correspondiente.

Pues bien, para facilitar estas operaciones de adaptación a la normativa europea, se han introducido una serie de cambios normativos de interés en el ordenamiento jurídico catalán:

\footnotetext{
${ }^{13}$ Tener en cuenta la Ley 20/2009, de 4 de diciembre, de prevención y control ambiental de las actividades (DOGC no 5524, de 11/12/2009).
} 
1. Por un lado, en cuanto a la actividad, la Generalitat de Cataluña ha aprobado un documento llamado "Criteris de qualificació de les modificacions com a substancials o no substancials" que establece que en el caso de las explotaciones ganaderas no se considerará cambio sustancial la modificación derivada de la adaptación de las instalaciones a la normativa de bienestar animal. La adaptación de las explotaciones ganaderas a esta normativa, si mantienen la capacidad productiva autorizada, se califica como no sustancial. Esto significa que los titulares de las explotaciones ganaderas no tendrán que tramitar ningún nuevo permiso ante la Administración autonómica.

2. En cuanto a las obras que deban realizarse en las instalaciones, puede plantearse el problema de que si desean mantener la misma capacidad productiva, se vean obligados a ampliar las mismas y ello puede ser que entre en contradicción con el planeamiento, por ejemplo, porque no se cumplan entonces, determinadas distancias $\mathrm{u}$ otro tipo de condicionantes.

En este caso, la norma de referencia en el ordenamiento jurídico catalán es el Texto Refundido de la Ley de Urbanismo, aprobado por el Decreto Legislativo 1/2010, de 3 de agosto (DOGC 5686, de 5/08/2010). El Parlamento de Cataluña aprobó la Ley 3/2012, de 22 de febrero, de modificación de la anterior (DOGC 6077, de 29/02/2012), que en materia de suelo no urbanizable -donde normalmente se emplazan este tipo de instalaciones- ha introducido algunos cambios significativos ${ }^{14}$.

\footnotetext{
14 Ley 3/2012, de 22 de febrero, de modificación del texto refundido de la Ley de urbanismo, aprobada por Decreto legislativo 1/2010, de 3 de agosto.

Artículo 14. Modificación del artículo 49 del texto refundido de la Ley de urbanismo (LCAT 2010\536).

"Se modifica el artículo 49 del texto refundido de la Ley de urbanismo (LCAT 2010\536), que queda redactado del siguiente modo:
} 
«Artículo 49. Procedimiento para la aprobación de determinados proyectos de nuevas actividades y construcciones en suelo no urbanizable

1. Las determinaciones del artículo 48 se aplican también a las siguientes actuaciones en suelo no urbanizable: a) Los proyectos de actividades y de construcciones directamente vinculadas a la explotación de recursos naturales.b) Los proyectos de nuevas construcciones a que se refiere el artículo 47.6. $b$, destinadas a vivienda familiar o alojamiento de trabajadores temporeros y los proyectos a que se refiere el apartado 2 en todos los casos en que incorporen dichos usos. En cualquier caso, los mencionados usos deben estar directa y justificadamente asociados a la explotación rústica de que se trate, y las construcciones deben constituir un conjunto integrado, adecuado al medio rural. c) La apertura o recuperación de vías de acceso, caminos y atajos, en caso de que la recuperación no esté integrada en un proyecto de actuación admitida en esta clase de suelo, tramitado de acuerdo con la legislación sectorial. d) Las estaciones de suministro de carburantes y de prestación de otros servicios de la red viaria. e) Las construcciones auxiliares destinadas a la actividad de turismo rural. f) Cualquier otra actuación que afecte a restos arqueológicos de interés declarado, acuíferos clasificados, zonas vulnerables o zonas sensibles declaradas de conformidad con la legislación vigente, yacimientos paleontológicos o puntos geológicos de interés.

2. Los proyectos de nuevas construcciones propias de una actividad agrícola, ganadera o, en general, rústica, si superan los umbrales establecidos en el planeamiento territorial y el urbanístico, salvo el supuesto del inciso final del apartado 3, deben someterse al informe de la comisión territorial de urbanismo que corresponda, que regula el artículo 50.1, con los mismos efectos vinculantes. Este informe ha de referirse a los aspectos de legalidad de los proyectos y al estudio de impacto e integración paisajística de la nueva construcción que el promotor del proyecto ha de presentar.

3. En el caso de proyectos que conlleven el establecimiento o ampliación de actividades ganaderas, han de someterse a información pública por un plazo de veinte días y al informe del departamento competente en materia de ganadería relativo al cumplimiento de los requisitos de distancias establecidos por la normativa sobre ordenación ganadera. La correspondiente licencia solo puede otorgarse si dicho informe es favorable. En caso de que dichos proyectos superen los umbrales a que se refiere el apartado 2, este informe y el proyecto tramitado deben aportarse conjuntamente con la solicitud del correspondiente informe de la comisión territorial de urbanismo que corresponda. Sin embargo, los proyectos relativos a actividades ganaderas preexistentes que, sin incrementar la capacidad productiva de las instalaciones, solo comporten obras para adaptar estas instalaciones a las exigencias derivadas de la legislación aplicable en materia de ganadería no requieren los informes mencionados, sino que quedan sujetos únicamente a licencia municipal.» 
El esquema que establece la modificación normativa introducida sería el siguiente:

- Establecimiento o ampliación de actividades ganaderas: requerirán un trámite de información pública por plazo de 20 días + informe del Departamento de la Generalitat competente en materia de ganaderia sobre el cumplimiento de los requisitos de distancias establecidos por la normativa sobre ordenación ganadera. La licencia correspondiente sólo se podrá otorgar si dicho informe es favorable.

Si estas instalaciones superan los límites que establece el planeamiento urbanístico y territorial deberá informar la Comisión territorial de urbanismo que corresponda.

- Instalaciones ganaderas que necesiten hacer obras para adaptarse a las exigencias derivadas de la legislación aplicable en materia de ganadería, cuando no se incremente la capacidad productiva: sólo requerirán licencia de obras.

Es decir, si la realización de los cambios necesarios en las instalaciones ganaderas no supone aumentar la capacidad productiva, sólo será necesaria licencia de obras. Si dichos cambios comportan un aumento de la capacidad productiva, en ningún caso será un límite o impedimento para que puedan llevarse a cabo, el hecho de que entren en contradicción con los condicionantes que establezca el planeamiento. En este caso, para salvar esta circunstancia deberá informar la comisión territorial de urbanismo que corresponda. 